\title{
As marcas corporais segundo a percepção de profissionais de saúde: adorno ou estigma?
}

\author{
Perceptions of healthcare providers toward body art: \\ adornment or stigma?
}

Mariana Malheiros Caroni ${ }^{1}$

Eloisa Grossman ${ }^{2}$

${ }^{1}$ Núcleo de Estudos da Saúde do Adolescente, Universidade Federal do Rio de Janeiro. Av. 28 de setembro 109/fundos Pavilhão Floriano Stoffel, Vila Isabel. 20551-030 Rio de Janeiro RJ. maricaroni@yahoo.com.br ${ }^{2}$ Faculdade de Ciências Médicas, Centro Biomédico, Universidade do Estado do Rio de Janeiro
Abstract Nowadays, body art is widespread, especially among adolescents. This qualitative study seeks to assess whether the use of body art interferes with how nursing assistants care for hospitalized adolescents and to identify factors that influence the perceptions of these health care providers. Nursing assistants working in an adolescent-specific ward were interviewed. After the analysis, dominant themes emerged from the narratives, allowing for a better understanding of how nursing assistants perceive tattoos and piercing. Some themes were recurrent, especially the association of body art with deviant behavior, erotic appeal, consumerism, courage, health risks, and psychic disorders. Religion and family values prevail over professional knowledge in how body marks are perceived. It may thus be inferred that a negative attitude toward body art is directly related to quality of care. The number of marks, their location, their type, and the definite/temporary character of tattoos and piercing interfere with the providers' interpretation. However, piercing and tattoos are important semiological tools and must be included in the script for the evaluation of adolescents.

Key words Tattooing, Body piercing, Adolescent, Nursing aides, Healthcare personnel
Resumo O uso de marcas corporais tem se tornado cada vez mais frequente, sobretudo entre adolescentes. Através de abordagem qualitativa, este estudo pretende avaliar se o uso de piercings e tatuagens afeta o cuidado prestado por auxiliares de enfermagem a adolescentes internados e identificar influências na formação dos significados atribuídos às marcas. Foram entrevistados auxiliares que trabalham em enfermaria específica para o atendimento de adolescentes. Após análise das entrevistas, foram formuladas categorias para melhor apreensão do sentido atribuído pelos auxiliares ao uso de marcas. Algumas categorias foram recorrentes, destacando-se a associação das marcas a: comportamentos de desvio; apelo erótico e consumismo; gesto de coragem; riscos de adoecimento e doença mental. Religião e valores familiares predominaram sobre a formação profissional em relação aos significados atribuídos ao objeto de estudo. Conclui-se que a visão negativa em relação às marcas relaciona-se diretamente ao cuidado. A quantidade de marcas, a localização, o tipo, a idade do adolescente e o caráter definitivo/transitório interferem na interpretação dos profissionais. Contudo, marcas corporais são ferramentas semiológicas importantes, devendo ser incluídas no roteiro de avaliação dos adolescentes.

Palavras-chave Tatuagem, Piercing corporal, Adolescente, Auxiliares de enfermagem, Pessoal de saúde 


\section{Introdução}

A adolescência é um período de transformações corporais, que ocorrem paralelamente à elaboração da identidade. O corpo transformado habilita os sujeitos a práticas inéditas, especialmente aquelas relacionadas à sexualidade. Durante este processo, as descobertas são vividas de maneira intensa. $\mathrm{O}$ adolescente é um ser intransitivamente apaixonado. $\mathrm{Na}$ sociedade ocidental contemporânea, para demonstrar suas paixões e atrair o olhar dos outros, algumas vezes, o adolescente usa seu corpo, marcado por vertiginosas mudanças, como estandarte.

O hábito de marcar o corpo acompanha a humanidade desde as mais antigas civilizações ${ }^{1}$. Ao longo da História, representou diferentes significados: de símbolos religiosos a signos de segmentação social ${ }^{2}$. No Ocidente, foi marca de tribos urbanas: punks, surfistas e motoqueiros ${ }^{3}$. Atualmente, as marcas corporais ganharam as ruas, estampadas ou fincadas na pele de adolescentes e jovens dos mais diversos grupos sociais ${ }^{4}$.

Embora tenha se popularizado, a aceitação social dessa prática não é universal. Além dos riscos à saúde associados ao procedimento ${ }^{5,6}, \mathrm{o}$ uso de piercings e tatuagens impõe risco adicional aos usuários: a estigmatização ${ }^{7}$. Nesse contexto, as marcas também influenciam a relação dos adolescentes com os profissionais de saúde. Stuppy et al. ${ }^{8}$ sugerem que indivíduos tatuados, especialmente adolescentes, podem ser alvo de uma visão negativa por parte dos profissionais, ao procurar atendimento nos serviços de saúde.

Embora a adolescência seja associada a vigor físico pleno, muitas vezes, durante esse período, o indivíduo vive uma experiência de adoecimento, sendo necessária a internação hospitalar. Durante a internação, há uma ruptura na rotina dos adolescentes, com perda do contato cotidiano com amigos e, muitas vezes, com a família ${ }^{9}$. A equipe de saúde assume, então, destaque na comunicação e no cuidado do adolescente internado.

Os profissionais de enfermagem, sobretudo os auxiliares, lidam de forma direta e constante com os pacientes e desempenham inúmeras funções, tais como: higiene, curativos e administração de medicamentos. Escutam lamúrias, choros, confidências. Manipulam corpos, muitas vezes de forma invasiva. Participam no desenvolvimento de atividades de promoção de saúde e de prevenção de agravos, assim como das reuniões de equipe.

Reconhecendo que o número de adolescentes com marcas corporais vem crescendo diariamen- te e que essa prática tem implicações no cuidado desses indivíduos, o presente estudo trata das tatuagens e piercings e da construção de estigmas. Tem como objetivo compreender as percepções de auxiliares de enfermagem acerca do uso dessas escrituras corporais pelos adolescentes internados. Buscou-se identificar as implicações da presença das marcas corporais no cuidado por eles prestado, na rotina do trabalho desenvolvido em uma unidade terciária específica para o atendimento de adolescentes.

\section{Métodos}

Foi utilizada abordagem qualitativa, que permitiu compreender profundamente valores, hábitos, concepções e atitudes do grupo pesquisado.

$\mathrm{O}$ estudo foi desenvolvido na enfermaria de adolescentes do Núcleo de Estudos da Saúde do Adolescente (NESA) da Universidade do Estado do Rio de Janeiro (UERJ), local de internações clínico-cirúrgicas. O NESA/UERJ é responsável pela atenção integral à saúde de adolescentes de 12 a 20 anos, funcionando como unidade docente-assistencial nos níveis de atenção primária, secundária e terciária.

Os sujeitos do estudo foram auxiliares de enfermagem que trabalham na enfermaria do NESA/UERJ. Os critérios de inclusão foram disponibilidade e interesse em participar da pesquisa. Dos profissionais convidados, dois se recusaram a participar, alegando problemas pessoais; um não compareceu no horário marcado. As entrevistas foram realizadas através do método desenvolvido por Cardoso ${ }^{10}$, de entrevistas em quatro módulos (contato, reconstrução da história de vida, temático, discurso livre). Foram realizadas na própria enfermaria, com duração entre 40 minutos e duas horas. Todas foram gravadas e, posteriormente, transcritas. A partir da análise, identificaram-se padrões, práticas e concepções acerca do objeto de estudo. O número de entrevistas foi considerado satisfatório quando as recorrências atingiram o que se convencionou chamar de "ponto de saturação".

Foram realizadas sete entrevistas, cinco com auxiliares do sexo feminino e duas com do sexo masculino. As idades variaram entre 28 e 49 anos. Todos eram naturais do Rio de Janeiro e o tempo de serviço na enfermaria variou entre cinco meses e 25 anos.

A análise das narrativas inspirou-se no modelo de conhecimento descrito por Carlo Ginzburg $^{11}$. Este modelo propõe que, ao invés de se 
atentar apenas para o óbvio, devem-se buscar as particularidades que traem o inconsciente, pois estas se constituem em signos involuntários capazes de referendar autenticidade. A técnica aplicada à leitura do discurso compreendeu algumas etapas. Na primeira, realizada durante as entrevistas, identificaram-se aspectos centrais relacionados ao objeto da investigação, bem como a indícios reveladores de significados, tais como: momentos de silêncio, interjeições, reticências, gestos e ênfases. Essas observações foram registradas em notas de campo.

Num segundo momento, correspondente à transcrição, considerou-se o observado na primeira fase e atentou-se para o que era recorrente nas diferentes falas. Na terceira fase, empreendida sobre o material transcrito, checaram-se as categorias comuns e procuraram-se variações e exceções a elas.

Processada a análise, a partir da organização e classificação do material, foram formuladas categorias que visaram melhor apreensão das redes de significado atribuídas pelos auxiliares ao uso de tatuagem e piercing pelos adolescentes.

\section{Resultados e discussão}

Nas entrevistas, buscou-se conhecer a história de vida e a trajetória profissional dos entrevistados, a fim de identificar possíveis aspectos relacionados à formação do significado atribuído ao uso de marcas corporais. O tempo de profissão dos entrevistados, assim como a variação etária não implicou diferença nos sentidos atribuídos às marcas corporais, contrariando a hipótese formulada previamente ao estudo de que a idade teria grande influência nas percepções acerca do uso de piercing e tatuagem.

A partir da escuta das histórias particulares de cada entrevistado foi possível identificar que a família desempenhou um papel de destaque na escolha da enfermagem como profissão, assim como a facilidade de inserção no mercado de trabalho. Os valores familiares, incluindo os preceitos religiosos, predominaram em relação aos saberes acadêmicos na gênese das concepções acerca das marcas corporais. Os sentidos atribuídos às marcas foram: comportamentos de desvio, apelo erótico e consumismo, gesto de coragem, riscos de adoecimento e doença mental.

A relação dos entrevistados com a família se mostrou intensa. Todos declararam ter sido bastante influenciados por seus pais, que, para a maioria, foram os principais modelos de vida, muitas vezes determinando suas escolhas: Então eu só fazia aquilo que fosse agradar o meu pai, não o que eu queria fazer... (E6).

A maioria das famílias adotava um método de criação rígido, com controle de horários e do círculo de amizades dos filhos. Contudo, o medo de decepcionar, a admiração e o respeito fizeram com que muitos dos entrevistados obedecessem às regras impostas e reconhecessem que os limites foram fundamentais na formação do seu caráter. Sou grato aos meus pais pela educação que me deram. Ajudaram a formar o homem que sou hoje... (E7).

A possibilidade escassa de diálogo nas famílias foi apontada como fator negativo. Temas relacionados à puberdade, à sexualidade e ao uso de drogas eram raramente discutidos. O mesmo ocorria em relação às marcas corporais. Quando o tema era trazido à tona, geralmente gerava reações de desaprovação, como aponta E4: ... uma vez na mesa de jantar eu falei: ah, eu queria fazer uma tatuagem que eu vi na televisão!... Então praticamente teve aquele transtorno todo na mesa de jantar! O jantar terminou...

As reações de reprovação eram mais evidentes nas famílias com membros ligados às forças armadas. Mas, mesmo nas mais liberais, o uso de marcas não era bem visto, sendo inclusive recomendada certa distância dos tatuados, porque não era pessoa pra andar com a gente, pessoa tatuada... (E1).

Alguns contaram que alguns membros da família, apesar das recomendações dos outros familiares, decidiram tatuar-se. Em geral, esses indivíduos foram estigmatizados como problemáticos, inconsequentes ou desrespeitosos. Em duas ocasiões mencionou-se o uso de tatuagem pelos filhos dos entrevistados. No caso de E6, essa atitude gerou desapontamento: Olha, parece que eu trouxe aquilo do meu pai. Eu levei, acho que uns três meses pra OLHAR a tatuagem dela. Não conseguia. Já no caso de E5, a tatuagem da filha foi encarada com mais tolerância, influenciando na realização posterior de uma tatuagem no próprio corpo, homenageando o neto recémnascido. Porém, mesmo após ter se tornado uma adepta da prática, o uso de marcas ainda é encarado por ela com ressalvas. Essa atitude ambivalente é percebida na maioria dos relatos; ao mesmo tempo em que não desejam adotar uma postura preconceituosa, declaram que o uso de piercing e tatuagem causa algum grau de incômodo.

A religião como elemento norteador de suas vidas esteve presente nas falas, muitas vezes desde a infância, como parte do cotidiano familiar: 
Eu fui criado a frequentar catequese, ir à igreja todos os domingos. Fiz primeira comunhão, catecismo e crisma... (E7).

Para alguns entrevistados, a religiosidade foi a válvula de escape para momentos de angústia. Eu sou evangélica. Ah, foi num momento que eu fiquei um pouco enferma, né? Aí minha mãe me chamou pra ir pra igreja. Eu fui num dia, gostei, aí comecei a frequentar... (E2).

Em outros casos, a busca por uma religião foi parte de um processo de crescimento pessoal, como conta E5: Hoje em dia, eu sigo a linha, a doutrina de Alan Kardec, que é o kardecismo. Que é um espiritismo MUITO bom, que eu encontrei várias respostas ...

Independentemente da crença, a religião tem grande influência na percepção dos entrevistados sobre as marcas corporais, na medida em que define as marcas como máculas do "corpo natural" ${ }^{12}$, feito à imagem e semelhança de Deus. Ideia explicitada por E2: Eu acho que se eu sou assim é porque Deus me fez assim, e assim ele me quer! Então quem sou eu pra tentar transformar o que Deus criou?

Em outros momentos, os valores religiosos são demonstrados pela associação de algumas marcas com rituais satânicos: $E$ tem alguns tipos de piercing que a pessoa coloca interno na região da testa que você fica com chifre! Você faz o garfo do diabo... (E7).

Assim, fica claro que, para os auxiliares que seguem alguma religião, o uso de marcas é associado a valores negativos. Alterar o corpo representaria uma profanação da imagem de Deus ${ }^{13}$.

Em relação à escolha profissional, os motivos que levaram os entrevistados a optar pela enfermagem foram variados.

A presença de profissionais de saúde no círculo familiar foi fundamental na escolha de dois entrevistados. As mães foram o principal modelo, segundo E6: Ela, muitas vezes, me levava com ela, na parte da tarde, no hospital...Eu pegava um scalpzinho escondido, levava pra casa, enchia o soro de água e minhas bonecas ficavam tudo encharcadas por dentro. Que eu deixava correr soro à vontade...(E6).

A maioria, porém, optou pela área devido à facilidade de inserção no mercado de trabalho através do curso técnico em enfermagem. Na enfermagem, como é que eu cheguei? Eu tive que trabalhar, né! ...Ah, pra trabalhar de enfermagem é mais fácil... (E1). Grande parte já tinha experiência profissional em outros campos, mas a escolha da enfermagem ocorreu pela maior estabilidade no emprego.
Para outro entrevistado, a possibilidade de vivenciar as histórias do noticiário policial fazia da enfermagem uma alternativa excitante: ...então eu via aquilo tudo no [hospital] Miguel Couto e de tarde escutava na patrulha da cidade e ficava ouvindo. Eu acho que isso foi me estimulando! Ver aquelas pessoas sofrendo ali, eu querendo ajudar... (E5). Nesse caso, o gosto pelo trágico foi o grande estímulo para seguir na profissão.

O curso de auxiliar foi descrito como direcionado aos aspectos utilitários da profissão. Você tem que aprender todo o conteúdo, né? As medicações, as diluições, pra que serve, pra que não ser$v e . . .(\mathrm{E} 4)$. O tema marcas corporais, embora considerado importante, não fez parte da formação acadêmica de nenhum dos entrevistados. As discussões sobre corpo se resumiam à necessidade do uso de biombo e à importância de lidar discretamente com a nudez dos pacientes. É o que o professor falou no primeiro dia de aula: na nossa profissão não existe sexo. Então você tem que mostrar total segurança pra ele [o paciente]! Porque você é profissional, você não ta ali pra observar nada no corpo dele... (E2).

Quanto aos significados atribuídos às marcas observou-se uma coerência com as visões de mundo dos entrevistados. Para melhor evidenciar o objeto deste estudo, optou-se por apresentá-los em tópicos.

\section{Comportamentos de desvio}

$\mathrm{O}$ ato de marcar o corpo, no Ocidente, sempre esteve associado a comportamentos desviantes ${ }^{14}$. Durante muito tempo, o fato de usar tatuagem ou piercing conferia a seus adeptos o status de aberração. No século XIX, a tatuagem era atração de circo em toda a Europa e na América. Homens e mulheres com corpos inteiramente cobertos de desenhos se apresentavam ao lado de animais malformados, anões, gigantes; ou seja, todo tipo de criatura considerada fora dos padrões ${ }^{15}$. Hoje, embora as modificações corporais tenham se tornado lugar-comum, esta prática ainda é, frequentemente, associada à anormalidade.

Durante as entrevistas, foi evidenciada consonância com esse pensamento, atribuindo-se o uso das marcas à vontade de romper com padrões estabelecidos. Em alguns casos, essa ruptura foi associada à rebeldia. Como E1, ao retratar sua experiência: Não podia furar a orelha, eu furei com 13 anos. Rebelde, né?. Ou no exemplo de E7, que relaciona as marcas a uma atividade ilícita, a pichação: ... eu acredito que, como um pichador, é uma forma de expressar vários sentimentos. 
Muitas vezes, esse comportamento foi considerado próprio da postura questionadora e transgressora do adolescente.

A prática de marcar o corpo é bastante frequente dentro dos presídios ${ }^{15}$. Assim, alguns entrevistados acreditam que as marcas, mais do que expressão de descontentamento, são indícios de envolvimento com práticas criminosas: ... a minha visão é essa. Você pega duas pessoas tatuadas, duas pessoas bonitinhas e bota lá na sala da polícia pra fazer reconhecimento, eu vou dizer: o primeiro e o terceiro são bandidos, traficantes, o outro é inocente e o outro nem desconfio dele, tão bonito... (E6). O uso de marcas é associado também ao pertencimento a facções criminosas, conforme apontado por E1: por exemplo, no Japão, que o pessoal que é tatuado é tudo da Yakuza, numa alusão aos integrantes da máfia japonesa, que tradicionalmente exibem corpos extensamente tatuados em sinal de lealdade e sacrifício ${ }^{15}$.

Outros auxiliares demonstraram preocupação diante de adolescentes com marcas por achar que a presença destas pode ser associada ao uso de drogas Poderia ser uma adolescente que não só com o corpo todo tatuado, ah, será que é também usuário de droga?(E4). Os profissionais de saúde têm grande preocupação em relação ao tema, com trabalhos que afirmam existir relação direta entre marcas e drogas, sugerindo que, diante de um adolescente com piercing e tatuagem, esse assunto deve ser extensamente debatido ${ }^{16}$.

\section{Apelo erótico e elemento constitutivo da sociedade de consumo}

O uso das marcas corporais como estratégia de sedução foi destacado pelos entrevistados. Os adornos serviriam para realçar zonas erógenas do corpo $^{17}$. Dependendo da localização da marca, esse objetivo fica mais evidente. No umbigo já passa a ser uma tatuagem sexy. E também na parte do cóccix... (E4).

Embora considerem que homens e mulheres se utilizam das marcas para chamar a atenção para seus corpos, em várias entrevistas seu uso como apelo erótico foi associado a estratégias femininas de conquista. Eu acho que as meninas quando jogam um piercing no umbigo, ela ta usando aquilo pra charme! (E5). As mulheres, ao demarcar regiões que são alvo da cobiça sexual masculina, potencializariam suas armas de sedução ${ }^{18}$, como descreve E7: ...na região próxima a região genital, a mulher costuma fazer uma tatuagem e deixar uma pontinha só aparecendo, pra que? Pra de fato despertar uma curiosidade!
A relação das marcas com o gênero também foi evidenciada a partir de definições de tipos de marcas e locais do corpo considerados femininos ou masculinos. Quanto às figuras, são consideradas femininas aquelas que remetem à delicadeza, sensualidade e submissão, como flores, fadas e borboletas. Segundo a tradição chinesa, a rosa representaria o amor e a fidelidade. Uma borboleta representaria a mulher enquanto um par de borboletas simbolizaria a felicidade conjugal ${ }^{15}$.

Algumas regiões do corpo são consideradas apropriadas para o uso de tatuagens e piercings em mulheres. Prática comum no Egito Antigo e, ainda hoje, em algumas tribos amazônicas, o uso de marcas no ventre e nos seios destaca o início do período fértil das mulheres ${ }^{15}$. Embora este ritual não seja comum nos centros urbanos, os entrevistados frequentemente associaram a presença de marcas no abdome, sobretudo no umbigo, à feminilidade, assim como nos quadris, virilhas e nuca.

Por serem associados ao poder, à bravura e à potência, totens animais são figuras muito populares entre homens adeptos da tatuagem ${ }^{15}$. Animais selvagens, assim perigosos. Cobra, uma águia! Acho que talvez tem a ver com: a força do animal está em mim... (E4). Para isso, são realizadas em regiões que ressaltam os músculos e a virilidade $^{18}$. O não cumprimento destes padrões é considerado inapropriado. Algumas vezes, os próprios entrevistados vêem isso como fruto de preconceitos arraigados. Em seguida, porém, deixam claro que ainda não estão preparados para a quebra de protótipos. Mas um piercing no umbigo [quando usado por homens], eu acho que seria uma coisa muito gritante. Agressivo aos olhos da sociedade (E7).

O uso de marcas com fim estético também foi apontado. Atualmente, a aparência corporal tornou-se central às noções de autoidentidade ${ }^{19}$. A moda crescente da tatuagem e do piercing acompanha esse processo de glorificação e exposição dos corpos.

Com isso, as modificações corporais tornaram-se requisito estético para a inserção no contexto urbano atual. E4 explica: Eu acho que a parte da tatuagem hoje em dia, ta sendo procurada, não só como artista, como pessoas também normais... justamente pra poder complementar a estética. As marcas tornaram-se, então, objetos de consumo.

Os adolescentes, particularmente vulneráveis às pressões exercidas pela sociedade de consumo, têm necessidade de serem aceitos, o que os expõe ainda mais aos ditames da mídia e da so- 
ciedade. É preciso ser popular. E3 cita a influência do grupo nesse momento, simulando um diálogo entre adolescentes: Ah, a gente sai à noite, fica legal você fazer uma tatuagem dessa à noite, você coloca uma roupa preta! Poxa, a gente vai pra boate, vai ficar ótimo quando aquela luz...

A partir do momento em que piercing e tatuagem estão na moda, ao escolher determinada marca o adolescente passa a pertencer à comunidade $^{20}$. E aí um vai copiando do outro, quando você vê...aumentou muito o indice de tatuagem (E6).

\section{A autenticidade da dor em resposta à anestesia sensorial}

A marca corporal, independentemente do tipo e da localização, envolve procedimentos dolorosos. Tanto durante a confecção quanto durante a cicatrização, caracterizada por reação inflamatória que, muitas vezes, perdura por longo período $^{21-23}$. Nas entrevistas, houve unanimidade em apontar a experiência dolorosa como fator negativo das marcas. Porque é uma coisa que vai te furando! Aquilo ali vai te furando! Então...qualquer furinho na sua pele, aquilo dói! (E3).

Algumas vezes, essa exposição à dor foi identificada como sintoma de transtornos psíquicos, como no depoimento de E6: ...não é possivel que uma pessoa SÃ queira se machucar tanto porque eu acredito que aquilo deve doer. Em outros casos, foi vista como forma de agressão a terceiros, já que, ao expor cortes e furos na pele, o adepto da marca corporal provocaria reações desagradáveis em quem o observa. Eu não gosto das coisas que violentam e quando você olha, te agride! Que parece que ta doendo, parece que rasgou! Aí eu acho feio, eu não gosto...(E5). Entretanto, a maioria identificou a disposição de se expor a uma experiência dolorosa como manifestação de coragem. É muita coragem. Porque eu...não ia ter coragem... (E2).

Alguns autores sugerem que o sofrimento presente na confecção das marcas corporais vem acompanhado de prazer, ligado à superação de limites $^{18,24}$. As marcas se apresentam como promessas de resgatar o corpo da "monotonia sensorial" das normas sociais, inseridas numa cultura de patologização da dor e do sofrimento ${ }^{19}$.

Nossos entrevistados reconhecem a autenticidade dessa dor, que se constitui numa resposta à anestesia sensorial típica da tardomodernidade. Algumas vezes, questionam se o que incomoda verdadeiramente é o sofrimento físico ou o fato de os adeptos das marcas terem coragem de enfrentar as normas vigentes, porque é preciso ter muita coragem pra você fazer alguma coisa e dizer pro mundo: eu sou isso, eu to aqui! (E1).

\section{O discurso do risco}

A associação do uso de marcas a riscos à saúde ou a comportamentos de risco foi enfatizada. Ao justificar sua não aceitação, os entrevistados destacaram diversas possibilidades de complicações clínicas relacionadas à prática.

A literatura científica destaca as complicações secundárias ao uso de piercing e tatuagem: infecções virais, bacterianas e fúngicas, sangramento, dermatite, formação de quelóides, fotossensibilidade e deformidades ${ }^{6,21,22,25}$. O medo de contrair infecções através do contato com fluidos corporais de pacientes com marcas é apontado por entrevistados: ...tem até aquele: ó, de repente é portador de HIV, a gente não sabe aonde ele foi feito essas tatuagens, né? Qual os cuidados que teve na hora, então, vamos ficar alerta, equipe! (E4).

Esse medo, muitas vezes, determina que alguns sejam mais cautelosos no manejo destes adolescentes. Como explica E7: ...de repente uma pessoa que eu puncionaria com uma simples agutha, o dele eu vou pegar com scalp. Uma proteção não só minha, quanto dele! Você fica sim, com o pé atrás, é involuntário... (E7).

Essa concepção representa o discurso do risco, defendido pela literatura científica e propagado pelos meios de comunicação de massa ${ }^{26}$. Contudo, discursos sobre saúde não se referem somente à saúde, fazem parte de um contexto econômico, político e social ${ }^{27}$.

Essa questão ficou nítida diante da preocupação em relação à dificuldade de inserção profissional dos adolescentes adeptos das marcas. Tatuagens e piercings foram apontados como fatores que gerariam dúvida sobre a credibilidade e competência profissionais. Acho que tira um pouco da sua imagem, da sua seriedade, alguma coisa desse tipo. E compromete... (E6).

Existe uma tensão latente entre ser "tatuado" e continuar sendo um cidadão produtivo, não rejeitado pela sociedade ${ }^{14}$. Nas relações de trabalho, essa dicotomia se exacerba, pois empregadores em potencial têm visão negativa em relação às marcas ${ }^{7,8223}$. Conforme explicita E7: se você pegar um cara como meu pai, por exemplo, que é mais conservador, a primeira coisa que vai dizer é: 'usa piercing, ta fora'...

Outro fator apontado foi o caráter definitivo de algumas marcas. Os adolescentes, vivendo uma fase de descobertas e construção, ainda não 
estariam preparados para tomar uma decisão definitiva. A gente passa por várias fases. Então agora na adolescência você quer fazer uma tatuagem, quer colocar um piercing. Mas mais tarde você fica um pouquinho mais madura, então 'não sei porque que eu fiz isso'... (E3). O momento adequado para a escolha não fica claro na opinião dos auxiliares. Essa questão envolve a dificuldade de conceituar adolescência a partir de parâmetros cronológicos ou legais e de definir início e fim do amadurecimento pessoal ${ }^{28,29}$.

Assim, piercing e tatuagem são percebidos de maneiras bem distintas, já que o piercing, pela facilidade de remoção, permite que o adolescente reverta sua decisão: ... a tatuagem você praticamente fixou ela! Tem tratamentos hoje aí mas mesmo assim fica uma marca. Mas o piercing, não. Se você realmente quiser...se arrependeu, pode mandar retirar, né? Então não tem problema nenhum. Piercing você ainda tem direito a se arrepender... (E4).

\section{Transtornos psíquicos - sensações de medo, repugnância e horror}

A presença de alguns tipos de marcas e sua localização foram apontados como sugestivos de transtornos psiquiátricos, com alguns desenhos (dragões, caveiras) associados a comportamentos violentos. A escolha desses temas objetivaria despertar sensações de incômodo nos demais: ...você vai tatuar alguém sendo esfaqueado no braço, uma caveira...tem coisas que são pesadas de se ver! (E1).

Alguns tipos de modificações foram considerados inaceitáveis. Escarificações e espaçadores foram associados à automutilação: Parece que você tá se MUTILANDO, entendeu? Então acho que isso não existe! (E3). A associação de marcas corporais com automutilação é frequente na literatura científica, apontando para um desejo autodestrutivo e índices aumentados de suicídio ${ }^{30}$. As modificações são identificadas como formas de automutilação, não apenas porque o corpo é apresentado como imperfeito ou disfuncional, mas porque são expressões de um indivíduo em sofrimento, que necessita de tratamento ${ }^{31}$.

Da mesma forma, existe forte resistência ao piercing genital, identificado como prática sadomasoquista. Porque um lugar tão sensivel, tão nosso, tão particular... Eu acho que pode ser por um motivo de prazer dessa pessoa... (E5). No dia a dia do profissional, a repugnância em relação ao piercing genital é evidente, entretanto, para não constranger os adolescentes, tentam disfarçar a desaprovação. Como explica E2: ...mas já que foi uma escolha da pessoa eu não posso deixar a pessoa perceber que é uma coisa que eu to achando super estranho.

Em relação à localização, o uso de marcas no rosto é repudiado; este é um lugar do corpo que deve permanecer imaculado. Como afirma Son$\operatorname{tag}^{32}$, embora a filosofia e a ciência modernas tenham repudiado a separação cartesiana entre mente e corpo, o status privilegiado do rosto é fundamental para a avaliação de beleza ou ruína física. Essa separação é traduzida nas imagens europeias que representam o martírio cristão, nas quais o rosto demonstra uma superioridade tranquila em comparação com o sofrimento do corpo.

Além disso, o uso de marcas em maior quantidade ou em grandes extensões corporais é considerado excessivo, descrito como tendência impulsiva, difícil de ser contida após a primeira marcação ${ }^{33}$, muitas vezes associada ao exibicionismo:

Acho que eu acima de duas tatuagens já acho que me incomoda porque já virou assim...fica uma palhaçada, né? Porque tem gente que usa isso como hobby. E dizem que quanto mais fazem, mais querem, né? Querem adquirir. Eu acho que aí vai se deparar com um corpo TODO tatuado, eu acho que...me incomoda, eu fico possesso, não gosto, que eu acho que a pessoa ta sendo muito assim, PRESENÇA, não sei dizer. Assim, como é que eu vou te dizer, é...chamativo demais! Ser diferente demais! (E4).

\section{As marcas na enfermaria de adolescentes}

O dia a dia de profissionais que trabalham numa enfermaria de adolescentes não é previsível ou monótono. Além de uma rotina atribulada, com grande exigência de rapidez e eficiência, surgem situações difíceis de lidar. Indivíduos na pujança de vida, atropelados pela enfermidade. Corpos em desenvolvimento, sexualidade a flor da pele. Expectativas frustradas e a possibilidade recorrente da morte numa fase em que a vida pulsa tão plena de experiências e realizações fazem parte desse universo, ao mesmo tempo motivador e angustiante.

Nas entrevistas ficou claro que os auxiliares gostam de cuidar de adolescentes. O tipo de trabalho realizado na enfermaria é considerado motivador, mas revela situações de estresse e sofrimento: Tem umas situações mais delicadas...eu lembro de pacientes muito jovens, você vê morrer, é muito triste... (E1).

Porém, o trabalho em equipe é apontado como suporte para tarefas muitas vezes árduas e 
desgastantes: Todo mundo se entrosa muito bem, se entende, a gente trabalha em prol do paciente, a qualidade é boa. Então isso foi me encantando... (E5). Alguns entrevistados ressaltam a importância de seu papel na equipe: Fazemos parte de uma equipe, sim! Mas a recuperação direta de um paciente é direta da enfermagem! Porque somos nós que damos a medicação no horário, somos nós que visualizamos os parâmetros pra passar pro médico... (E7).

A promoção de saúde é identificada como importante função dos profissionais de enfermagem $^{28,34}$. O ritmo acelerado de trabalho, a sobrecarga de tarefas e a ausência de embasamento teórico foram descritos como empecilhos no desenvolvimento de ações de educação para a saúde. A função de orientar, na maioria dos casos, foi considerada exclusiva da família.

Muito se discute sobre a importância das medidas educativas na atenção à saúde dos adolescentes. Porém, como afirma Borges ${ }^{35}$, "educar não é o mero exercício de um saber, e sim, aventura subjetiva marcada pela incerteza e reabertura permanente de enigmas para cada um dos que embarcam nesta viagem”. É via de mão dupla, um ir e vir entre educador e educando, é dinamismo e não fixidez a esquemas pré-concebi$\operatorname{dos}^{36}$. Muitas vezes, por mais interesse que tenham no seu trabalho, nos adolescentes e nas suas famílias, é difícil para o profissional de saúde desempenhar esse papel. Sobretudo quando o tema a ser abordado envolve paixões e contradições, como as modificações corporais.

Em relação às marcas, todos relataram aumento da prevalência nos adolescentes internados, sobretudo do piercing. Quando questionados sobre a forma de lidar com esses pacientes, se mostraram preocupados em não adotar posturas discriminatórias. Porém, nas oportunidades de discussão do tema com os adolescentes, deixaram clara sua visão contrária à prática.

O uso de marcas, segundo os entrevistados, não é tópico presente nas discussões de equipe. Entretanto, todos reconhecem a importância do tema e consideram positiva a introdução do assunto em discussões futuras.

\section{Conclusões}

A semiologia é a base do raciocínio clínico, que, por sua vez, é o alicerce das tomadas de decisão no cuidado de indivíduos doentes. A correlação de sinais e explicações fisiopatológicas é a base para a formulação de hipóteses diagnósticas. Nesse processo, é fundamental o chamado "olhar clínico”. Este estudo chama a atenção para a importância da inclusão das marcas corporais no roteiro semiológico para avaliação de adolescentes, trazendo à tona a urgente tarefa de decifrarem-se os enigmas escondidos nas marcas, incluindo-as no rol de sinais a serem valorizados e interpretados. Como afirma Birman ${ }^{37}$, no deserto discursivo do mundo pós-moderno, essas escrituras, muitas vezes, assumem o lugar e a função da voz.

Mikhail Bakhtin, historiador da literatura e filólogo soviético, através de sua teoria enunciativa, argumenta que não há enunciados neutros; os enunciados emergem em contextos culturais, plenos de significados e valores, como atos responsivos ${ }^{38}$. Tomando como referência esse autor e encarando-se as escrituras corporais como enunciados, pode-se inferir que elas não só designam objetos, mas traduzem tomadas de posição. Portanto, piercings e tatuagens são elementos semiológicos importantes, que muito informam a respeito da história de quem os utiliza. Charon $^{39}$ assegura que os corpos são textos a serem lidos e que histórias podem ser contadas a partir das cicatrizes e dos registros corporais de fatos vividos.

No presente estudo, em conformidade com estudos anteriores, constatou-se que os auxiliares de enfermagem entrevistados associam o uso de marcas, sobretudo por adolescentes, a ideias negativas preconcebidas e passíveis de generalização. Demonstrou-se ainda que a quantidade de marcas, a localização, o tipo de desenho (com padrões distintos relacionados ao gênero) e o caráter definitivo/transitório (diferenciando tatuagens e piercings) têm importante papel na construção de juízos de valor.

Seguindo as recomendações de Ginzburg ${ }^{40}$, que emprega a categoria "estranhamento" como ponto de partida para uma atitude moral diante do mundo, ousa-se aqui recomendar que para realmente ver, ler e interpretar as marcas corporais deve-se primeiramente olhá-las como se não tivessem nenhum sentido, tal como códigos a serem desvendados. A partir desse primeiro passo, buscar-se-ia entendê-las no contexto particular de cada paciente. 


\section{Colaboradores}

MM Caroni trabalhou na concepção, metodologia, pesquisa, análise e interpretação dos dados e na redação do artigo. E Grossman trabalhou na concepção, orientação do trabalho, revisão crítica e aprovação da versão a ser publicada.

\section{Referências}

1. Muldoon KA. Body piercing in adolescents. J Pediatr Health Care 1997; 11(6):298-301.

2. Braverman PK. Body art: piercing, tattooing and scarification. Adolesc Med 2006; 17(3):505-519.

3. Pessanha DT. Intensidades corporais e subjetividades contemporâneas: uma reflexão sobre o movimento da body modification [dissertação]. Rio de Janeiro: Pontifícia Universidade Católica; 2006.

4. Carrol ST, Riffenburgh RH, Roberts TA, Myhre EB. Tattoos and body piercings as indicators of adolescent risk-taking behaviors. Pediatrics 2002; 109(6):1021-1027.

5. Schmidt M, Armstrong ML. Tattooing and body piercing. Up To Date Online 17.2. [site] 2009 [cited 2009 Aug 19]. Available from: http://www.uptodate. com/online/content/topic.do?topic Key=adol_med /3037\&selectedTitle $=1 \sim 53 \&$ source $=$ search_result

6. Beers MS, Meires J, Lofiz, L. Body piercing, coming to a patient near you. Nurse Pract 2007; 32(2):55-60.

7. Resenhoeft A, Villa J, Wiseman D. Tattoos can harm perceptions: a study and suggestions. J Am Coll Health 2008; 56(5):593-596.

8. Stuppy DJ, Armstrong ML, Casals-Ariet C. Attitudes of health care providers and students towards tattooed people. J Adv Nurs 1998; 27(6):1165-1170.

9. Ruzany MH, Pepe CCCA, Aquino JHW. A internação do adolescente traz repercussões em sua vida e em sua família. Cad Saude Colet 2004; 12(2):105-119.

10. Cardoso MHCA. Programa de história oral: os quatro módulos, método e prática. Hist Cad 1986; 4(1):29-35.

11. Ginzburg C. Sinais: raízes de um paradigma indiciário. In: Ginzburg C, organizador. Mitos, emblemas e sinais. São Paulo: Schwarcz; 1989. p. 143-79.

12. Prado Filho K, Trisotto S. O corpo problematizado de uma perspectiva histórico-política. Psicol Estud 2008; 13(1):115-121.

13. Falk P. Written in the flesh. Body and society 1995; 1(1):95-105.

14. Pérez AL. A identidade à flor da pele: etnografia da prática da tatuagem na contemporaneidade. MANA 2006; 12(1):179-206.

15. Araujo L. Tatuagem, piercing e outras mensagens do corpo. São Paulo: Cosac Naify; 2005.

16. Roberts TA, Ryan SA. Tattooing and high-risk behavior in adolescents. Pediatrics 2002; 110(6):1058-1063.

17. Ory P. O corpo ordinário. In: Corbin A, Courtine J, Vigarello G, organizadores. Historia do Corpo: as mutações do olhar, o século XX. Petrópolis: Vozes; 2008. p. 155-195.

18. Sabino CR, Luz MT. Tatuagem, gênero e lógica da diferença. Physis 2006; 16(2):251-272.

19. Ortega F. Das utopias sociais às utopias corporais: identidades somáticas e marcas corporais. In: Almeida MIM, Eugenio F, organizadores. Culturas jovens, novos mapas do afeto. Rio de Janeiro: Jorge Zahar; 2006. p. 42-58.

20. Scalozub LT. El protagonismo del cuerpo en la adolescência. Psicoanálisis 2007; 29(2):377-391. 
21. Pérez-Cotapos ML, Cossio ML. Tatuajes y perforaciones en adolescentes. Rev Med Chil 2006; 134(10): 1322-1329.

22. Mc Guiness TM. Teens \& body art. Journal of Psychosocial Nursing 2006; 44(4):13-16.

23. Stirn A. Body piercing: medical consequences and psychological motivations. Lancet 2002; 361(9364): 1205-1215.

24. Pires BF. O corpo como suporte da arte. Rev Latinoam Psicopat Fund. 2003; 6(1):76-85.

25. Diccini S, Nogueira AMC, Sousa VD. Body piercing among brazilian surgical patients. AORN J 2009; 89(1):161-165.

26. Castiel LD. Vivendo entre exposições e agravos: a teoria da relatividade do risco. Esterisco. [site] 2003 [acessado 2009 jul 19]. Disponível em: http://www4. ensp.fiocruz.br/projetos/esterisco/iniciol.htm

27. Castiel LD, Diaz CA. Discursos sobre riscos e comportamentos sadios baseados em evidências. In: Castiel LD, Diaz CA, organizadores. A saúde persecutória: os limites da responsabilidade. Rio de Janeiro: Fiocruz; 2007. p. 25-33.

28. Cano MAT, Ferriani MGC, Alves AC, Nakata CY. A produção do conhecimento sobre adolescência na enfermagem: período 1983 a 1996. Rev latinoam enfermagem 1998; 6(1):91-97.

29. Birman J. Tatuando o desamparo: a juventude na atualidade . In: Cardoso MR, organizador. Adolescentes. São Paulo: Escuta; 2006. p. 25-43.

30. Hicinbothem J, Gonsalves S, Lester D. Body modification and suicidal behavior. Death Stud 2006; 30(4):351-363.

31. Ortega F. O corpo incerto: corporeidade, tecnologias médicas e cultura contemporânea. Rio de Janeiro: Garamond; 2008.

32. Sontag S. Aids e suas metáforas. São Paulo: Companhia das Letras; 1989.

33. Almeida MIM. Tatuagem e subjetividade: reflexões em torno do imaginário da epiderme. Interseções. Revista de Estudos Interdisciplinares 2001; 3(1):91-109.

34. Gir E, Nogueira MS, Pelá NTR. Sexualidade humana na formação do enfermeiro. Rev latinoam enfermagem 2000; 8(2):33-40.

35. Borges SN. Metamorfoses do corpo: uma pedagogia freudiana. Rio de Janeiro: Fiocruz; 1995.

36. Grossman E. O médico de adolescentes e seu ofício: reflexões sobre as normas e a prática [dissertação]. Rio de Janeiro: Instituto Fernandes Figueira, Fiocruz; 1995.

37. Birman J. Escrituras corporais. Mente \& Cérebro. In: Birman J. O olhar adolescente, n. 1. São Paulo: Duetto; 2007. p. 46-53.

38. Bakhtin M. Questões de literatura e de estética: a teoria do romance. São Paulo: Hucitec; 2002.

39. Charon R. Narrative medicine: honoring the stories of illness. New York: Oxford University Press; 2006.

40. Ginzburg C. Olhos de madeira: nove reflexões sobre a distância. São Paulo: Companhia das Letras; 2001. 